and research and have contributed articles and papers to journals. Many have planned and developed new services for their Health Authorities. They have the experience of being consultants.

As far as I know, and as demonstrated by actual experience, Members of the Royal College of Psychiatrists who have had no SR training have no difficulty fulfilling the duties and responsibilities of consultants in clinical work, teaching, research or administration. There is also nothing to suggest that their colleagues who have had the full SR training make better or more competent consultants. (If there are data to the contrary, could the College make these available to us through the pages of the Bulletin?)

There is no doubt that, having become a Member of the Royal College of Psychiatrists, a doctor does need a further period of training and experience in order to qualify for appointment to a substantive consultant post. However, there do not appear to be real or demonstrable grounds for the insistence on formal SR training as a sine qua non for qualification for these appointments.

The point I would like to make is that this requisite further experience could be obtained either through the formal SR training scheme, or through working as a locum consultant.

My recommendation is that, in order to qualify for appointment to a substantive consultant psychiatrist post, the candidate would either have undergone the full four-year SR training, or been in continuous, locum consultant appointments for the same period, with at least two years devoted to the specialty in which the candidate is interested. In either case, the candidate would need to have shown interest in academic matters, and have good references.

Abraham Cowley Unit

I. O. AZUONYE

St Peter's Hospital

Chertsey, Surrey KT160QA

\section{JCHPT requirements regarding locum consultant posts - a warning letter}

DeAr Sirs

There are a number of post-membership psychiatric trainees who, for one reason or another have not achieved senior registrar appointments but who have had alternative psychiatric experience, not infrequently in extended locum consultant posts. These doctors are now experiencing serious difficulties in progressing their careers to a substantive consultant appointment.

We wish to re-affirm the importance which the JCHPT and the College attach to higher training in psychiatry beyond the MRCPsych level for all trainees aspiring to consultant appointments. Higher training in psychiatry is normally arranged so as to provide a grading of supervised responsibility from post to post. An unsupervised locum consultant post cannot substitute for this aspect of training otherwise it would be appropriate simply to proceed from registrar to consultant, a procedure which neither the JCHPT nor the college would accept. It is for these reasons that the JCHPT Handbook (1987 edition) clearly indicates that consultant locums should be undertaken only in the latter stages of higher training and then for no longer than three months. We sympathise with individuals who have undertaken locum consultant appointments in order to help provide a service where it has not been possible to make a substantive appointment and who may have been advised inappropriately. However, the present Handbook is clear concerning the regulations and the revised Handbook, which will appear later this year, will contain a statement emphasising the danger of taking consultant locums for too long a period and at too soon a point in a training career.

The College has been particularly successful in acquiring a further 90 senior registrar posts following the JPAC negotiations. These posts will in future help to solve the bottleneck existing between general and higher professional training. However, in the meantime we strongly recommend trainees to familiarise themselves with the contents of the Handbook regarding training requirements.

J. R. M. COPELAND Chairman Joint Committee of Higher Psychiatric Training (See pp. 543-548)

\section{Requests for early film footage}

DeAr SIRS

I am a film researcher working on a television series for $B B C 2$ on the social history of sexual attitudes in Britain during this century.

I am trying to find early film footage which shows life in mental institutions, 'mother and baby' homes and VD hospitals/clinics.

I would be most grateful to know if anyone knows of such film. Maybe it was amateur film shot by a member of staff of the institution or maybe it was an 'instructional' film that has been kept within the hospital archives.

We are aware that the contents of such films would have to be treated with extreme sensitivity and would like to stress that the programmes will be a serious and detailed history of the subject area.

Domino Films

MAGGI COOK

8 Stockwell Terrace

London SW9 0QD 